\title{
Orthographic-phonological links in the lexicon: When lexical and sublexical information conflict
}

\author{
JEESUN KIM ${ }^{1}$, MARCUS TAFT ${ }^{2}$ and CHRIS DAVIS ${ }^{1}$ \\ ${ }^{1}$ Department of Psychology, School of Behavioural Sciences, The University of Melbourne, \\ Parkville, Australia; ${ }^{2}$ Psychology Department, University of New South Wales, Sydney, \\ Australia
}

\begin{abstract}
At what level of orthographic representation is phonology linked in the lexicon? Is it at the whole word level, the syllable level, letter level, etc.? This question can be addressed by comparing the two scripts used in Korean, logographic hanja and alphabetic/syllabic hangul, on a task where judgments must be made about the phonology of a visually presented word. Three experiments are reported that used a "homophone decision task" and manipulated the sublexical relationship between orthography and phonology in hanja and hangul, as well as the lexical status of the stimuli. For both hanja and hangul word targets, subjects showed a high error rate in correctly judging that there was another word identically pronounced with it when sublexical information was non-supportive of whole-word homophony. It is concluded that the process of making a homophone decision reflects the relationship between orthography and phonology as mediated through sublexical units activated from orthography to phonology and vice versa (called "Orthography-Phonology-Orthography Rebound" or "OPO Rebound"). The results are explained and discussed within a multilevel interactive activation model with orthographic units linked to phonological units at each level.
\end{abstract}

Key words: Homophones, Lexical processing, Orthography, Phonology, Sublexical processing

\section{Introduction}

No matter what type of script it is written in, a printed word is always associated with a pronunciation. The primary function of orthography is that of visually communicating the spoken words of a language. The question that will be addressed here is how this link between orthography and phonology is represented mentally. The options appear to be the following.

1. Grapheme-phoneme conversion rules. One way of extracting pronunciation from orthography is to convert the individual graphemes ${ }^{1}$ into their phonemic equivalents by means of grapheme-phoneme conversion (GPC) rules. Thus, CAT will be pronounced $/ \mathrm{kæt} /$, via the rules $\mathrm{C}=/ \mathrm{k} /, \mathrm{A}=/ \mathfrak{x} /$, and $\mathrm{T}=/ \mathrm{t} /$. Nonwords, like $\mathrm{CAG}$, can be pronounced using exactly the same mechanisms. Where the GPC approach falls down, however, is when 
it comes to pronouncing irregular words whose pronunciation cannot be predicted from the individual graphemes, like YACHT, or the even more extreme case of Chinese logographic script where there are no graphemes at all (Henderson, 1982).

2. Whole-word pronunciations. The existence of irregular words and Chinese characters necessitates the involvement of lexical information in pronunciation, at least in those cases. The obvious way to determine the phonology of such orthographic forms is to consult lexical memory where this specific information is stored (e.g., YACHT $=/$ jot/). The storage of whole-word pronunciations that can be "read out" when required is, of course, the simplest possible description of orthographic-phonological links in the lexicon. If it is true, though, there needs to be some additional mechanism for pronouncing nonwords, since these are not stored in lexical memory. Such a mechanism could be the GPC rule system (e.g., Coltheart, 1980 ) or it could be some analogical process by which nonwords are constructed from word pronunciations, for example, pronouncing CAG on the basis of the first part of CAT and the last part of RAG (e.g., Humphreys \& Evett, 1985). This latter view presupposes that the lexical representation of the orthographic-phonological links is structured in such a way that it is clear that, for example, it is the AG part of RAG that is pronounced /æg/, and not just the G.

3. Hidden units. The analogy notion is akin to the proposal of Seidenberg and McClelland (1989) that orthographic-phonological links are represented in a set of distributed "hidden" units that mediate between orthographic units (representing letters) and phonological units (representing phonemes). The state of these hidden units develops in response to the statistical characteristics of the letter-sound pairings to which the system is exposed. That is, the hidden units represent statistical regularities that occur across the orthographic, phonological (and semantic) domains of a language without the need to specify what those patterns actually are. All letter strings are pronounced via activation of these hidden units, both words and nonwords. Given that nonwords are pronounced on the basis of recurrent orthographicphonological relationships that exist in the language, this is functionally equivalent to pronunciation by analogy.

However, there have been criticisms that the Seidenberg and McClelland model fails to pronounce nonwords as effectively as humans do (Besner, Twilley, McCann \& Seergobin, 1990). In response to this, Plaut, McClelland, Seidenberg and Patterson (1996) introduced sublexical structures into the model. In particular, the orthographic input units are structured as graphemes 
rather than individual letters so that, for example, EA, EE, EI and EU all form units (in addition to E, A, I, and U), and furthermore, the graphemes are specified as either comprising an onset (i.e., initial consonant or consonant cluster), a vowel, or a coda (i.e., final consonant or consonant cluster).

From an analysis of what the hidden units might represent, Plaut et al. (1996) conclude that they incorporate information about both the individual graphemes and some higher-order orthographic structure. Indeed, based on the work of Treiman, Mullennix, Bijeljac-Babic, and Richmond-Welty (1995), Plaut et al. (1996) have suggested that appropriate vowel pronunciations would be assisted if a network developed hidden units that respond to particular combinations of orthographic vowels and codas (i.e., word "bodies"). This suggestion is consistent with other evidence that perhaps the most important higher-order orthographic structure is the body of a word, which is the orthographic equivalent of the phonological "rime" (see also, Bowey, 1990; Kay \& Bishop, 1987; Taraban \& McClelland, 1987; Treiman \& Chafetz, 1987; Treiman, Goswami \& Bruck, 1990; Treiman \& Zukowski, 1988). The body is simply the vowel+coda (e.g., the AT of CAT, the OUTH of MOUTH).

This concept of a body is incorporated into another model (namely the multilevel hierarchical model) that is a more concrete description of the system than that of Plaut et al. (1996) in that it specifies the types of unit that are activated when phonology is derived from orthography.

4. Multilevel hierarchical activation. Notions of interactive-activation (e.g., Dell, 1986; Glushko, 1979; McClelland, 1987; McClelland \& Rumelhart, 1981; Rumelhart \& McClelland, 1982) were adopted by Taft (1991) to develop a multilevel hierarchical model. In this description of the system, activation can occur at different levels of representation potentially ranging from single letters up to whole words, in which orthographic units are associated with phonological units. Activation can spread from the graphemic level or phonemic level (according to the modality of the stimulus), to higher orthographic and phonological units via connections between the different levels, and activation can feed back from the higher level units to the lower level units in the same manner. In addition, activation can pass between orthographic and phonological units at the same level. If we assume that the hierarchy of levels is the same for orthography and phonology, we can suggest the structure depicted in Figure 1 (after Taft, 1991, 1994).

In this version of the multilevel hierarchical model, phonology is linked to orthography at the grapheme, body, morpheme, and word levels. When a word is visually presented, the phonological units, which are activated at all these levels, are used to generate a pronunciation. It may in fact be the case 


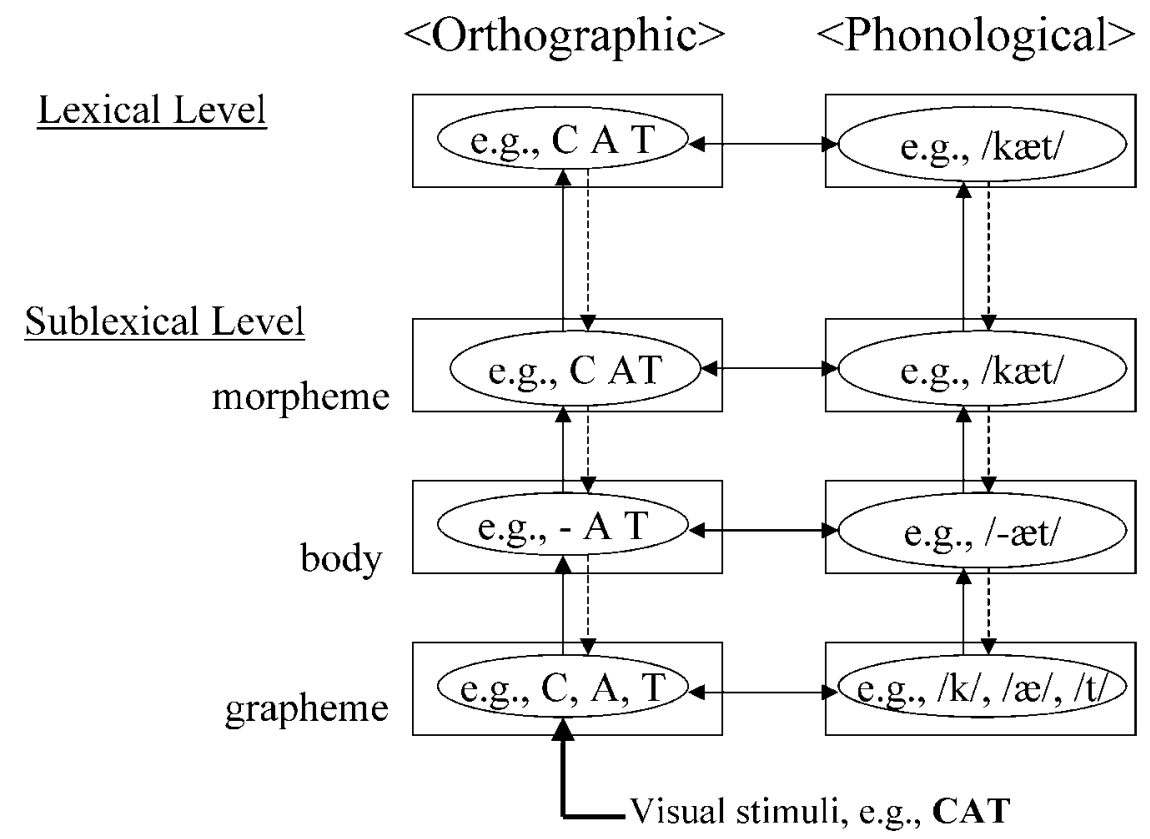

Figure 1. A version of the Multilevel Hierarchical model.

that the word level representations are redundant and could be replaced by modality-free "concept" level representations (as suggested by Taft, 1991). In this case, activation in the units representing the individual morphemes of a word would combine to feed directly to the activation of the meaning of the word. Word level units are included here, however, for clarity of exposition, but also because they provide a natural way to explain idiosyncratic pronunciations of polymorphemic words, like ASCERTAIN and BREAKFAST, which would be hard to generate from morpheme units alone (unless these words were actually considered to be monomorphemic).

If orthographic and phonological units at the word level are included, it is then a debatable point whether there needs to be orthographic-phonological links at the morpheme level as well (see Taft, 1994; Taft \& Zhu, 1995), but there is considerable evidence that morphemic information is represented in the lexicon at least in terms of orthography (e.g. Burani, Salmaso \& Caramazza, 1984; Fowler, Napps \& Feldman, 1985; Taft, 1979, 1981; Taft \& Forster, 1975). For instance, Burani et al. (1984) and Taft (1979) demonstrated that the recognition of a polymorphemic word is influenced by the frequency of its stem morpheme independent of the frequency of the whole word. More recently a number of studies have used various priming methodologies to demonstrate that morphological structure plays a role in word 
recognition (e.g., Drews \& Zwitserlood, 1995; Rastle, Davis, Marslen-Wilson \& Tyler, 2000; Stolz \& Besner, 1998).

What has been covered so far, then, are possible conceptualizations of the way in which orthography is linked to phonology in lexical memory. The issue of which framework is most helpful in understanding the relationship between print and sound will be addressed by the present research, using a task which specifically requires readers to respond to the phonological characteristics of visually presented stimuli. In particular, participants are presented with a stimulus presented in orthographic form, and are required to respond whether or not there exists a word in the language that is pronounced identically to that stimulus item, but is spelled differently. This is the "homophone decision" task previously reported by Taft (1984) and Taft and Chen (1992) with words as stimuli (e.g., "yes" for WEAK, "no" for YEAR), and Taft (1982) and McCann, Besner and Davelaar (1988) with nonwords as stimuli (e.g., "yes" for BRANE, "no" for PRAKE). Such a task presents readers with an orthographic stimulus and forces them to engage the orthographic-phonological links that are the focus of interest here. Of course, a simple naming task would do the same thing, but a homophone decision task allows a manipulation of the relationship between a homophonic item and its partner, and from this we can draw inferences about the nature of the orthographic-phonological links that are engaged. How could homophony be determined according to the models outlined above?

If using GPC rules, the letter string (e.g., WEAK) would be converted into its pronunciation (i.e., /wi:k/) and the lexicon would then be addressed via this phonological code. Once the lexical entry of a word is accessed (i.e., either the entry representing WEAK or the entry representing WEEK), the orthographic representation stored in that entry can be checked back to the original stimulus. If it is different from the orthography of the stimulus (as in the case of WEEK), a judgment can be made that there does exist a word homophonic with the stimulus. If, on the other hand, the accessed orthographic representation matches the stimulus (as in the case of WEAK), an attempt would presumably be made to access a different entry whose orthography was different. If this were not successful (e.g., in the case of YEAR), a "non-homophone" response can be made.

It might be thought that a homophone decision could simply be based on whether or not more than one lexical unit is activated on the basis of the phonologically recoded stimulus without any checking of orthography. However, if so, homographs like PORT, which have two lexical entries, would always be inappropriately classified as (heterographic) homophones.

As pointed out earlier, GPC rules can only be successfully used with regular words or nonwords. Therefore, if using GPC rules alone, it would 
be impossible to say that the irregular word BREAK had a homophonic partner (BRAKE), since the rules would generate the pronunciation /bri:k/ instead of /breIk/, and this would not be found in the lexicon. Given that it cannot be known a priori whether a letter-string is irregular or regular, the pronunciation for all words must be sought within the lexical information stored for the whole word. Since the GPC route is nevertheless required for pronouncing nonwords, as they have no lexical representation, the most efficient way of generating pronunciations from any letter-string would be to attempt access via both the GPC route and the direct lexical route in parallel. This is the Dual-Route Model (e.g., Coltheart, 1980; Coltheart, Davelaar, Jonasson \& Besner, 1977) or the more recent Dual Route Cascade (DRC) model (Coltheart, Curtis, Atkins \& Haller, 1993; Coltheart, Rastle, Perry, Langdon \& Ziegler, 2001). The lexical route will succeed when the stimulus is a word, and the GPC route when the stimulus is a nonword.

In accordance with the DRC Model, homophony could be determined when the orthographic representation of the stimulus (e.g., WEAK) accesses lexical information that specifies its pronunciation $(/ \mathrm{wi}: \mathrm{k} /)$ and then this pronunciation is fed back into the orthographic lexical system in order to ascertain whether or not a different word can be accessed on the basis of phonology (i.e., WEEK). The same idea would hold for nonword stimuli (e.g., BRANE), but this time the pronunciation of the stimulus would be generated via GPC rules.

When it comes to considering how a hidden unit model can be used to determine homophony, the situation is less clear. Plaut (1997) has modeled accurate lexical decision performance in terms of a semantically based criterion (based upon average semantic stress, see Plaut, 1997). However, something akin to this procedure would not be appropriate for homophone decision because a decision based purely upon semantic activation would always misclassify homographs. It is of course likely that some features of this model could be used to carry out homophone decisions. However, as specific proposals would need to be tested using simulations, it is difficult to make predictions about homophone decision results and, as such, we will not consider the parallel distributed approach further here.

The multilevel hierarchical model is able to provide a more explicit description of how homophony could be determined within an activation system. Homophony is represented in the system in terms of non-isomorphic associations between orthography and phonology (see Figure 2). At the morpheme level (equivalent to the word level in the case of monomorphemic words), homophonic pairs are represented by two orthographic units (e.g., WEAK and WEEK) linked to a single phonological unit (/wi:k/). The term "morpheme" is being used here rather loosely to mean "morphemic form". 


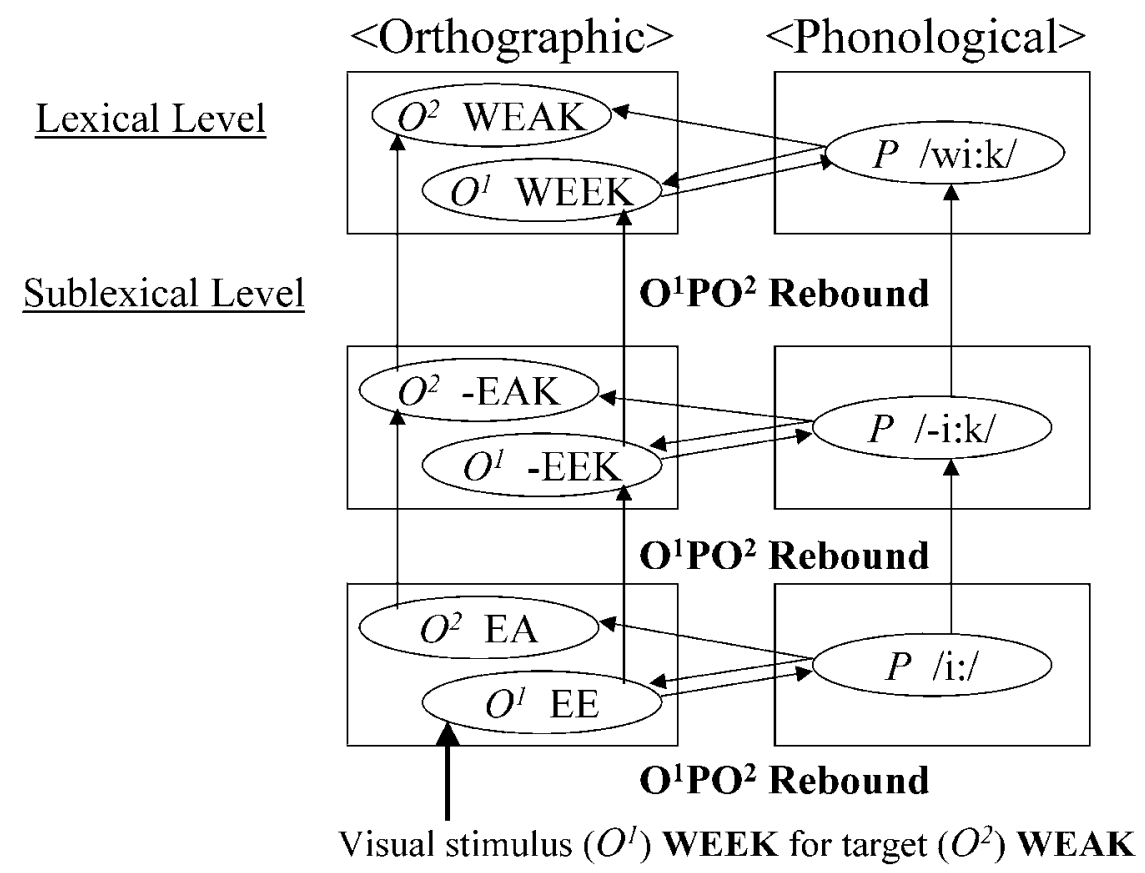

Figure 2. Homophone judgement in Multilevel Hierarchical Model. Note that $O^{1}$ refers to orthographic units activated from the presented stimulus and $O^{2}$ to target homophone units. Likewise $P\left(P^{1 \& 2}\right)$ stands for corresponding phonological units.

As such, there is only one representation postulated for /wi:k/ despite the fact that there are two different morphemes with the same form /wi:k/. The implications of this will be considered later.

When a stimulus word is presented (e.g., WEAK), its orthographic morpheme (word) unit becomes activated and automatically sends activation to its phonological morpheme (word) unit (/wi:k/). This, in turn, sends activation back to both of the orthographic units that are linked to it (WEAK and WEEK). We will term this pathway of activation "OrthographicPhonological-Orthographic Rebound" or "OPO Rebound" (see Taft \& van Graan, 1998; Stone, Vanhoy \& van Orden, 1997, for a similar concept). When a different orthographic unit to the one representing the stimulus item (the target homophone) is activated via OPO Rebound, a "homophone" response can be made. A "non-homophone" decision would be made when it is determined that no orthographic word unit other than the one corresponding to the presented stimulus is sufficiently active. Thus, factors that modulate the activation of the target's orthographic unit will directly affect the probability that a correct homophone decision will be made. 
In general, when a stimulus word has a homophonic partner, it will be the presented word which will be the most strongly activated since it is gaining maximal support from activation feeding up from the lower, sublexical levels. However, the homophonic partner can also benefit to some extent from activation coming up from the sublexical levels. This is because OPO Rebound will be occurring at all levels of unit: At the body/rime level, the orthographic unit EAK will activate the phonological unit /i:k/ which, in turn, will send activation back to both EAK and EEK, and similarly, EA will activate EE via /i:/ at the grapheme/phoneme level.

Support for the idea that sublexical units play a role in determining homophony comes from a study by Taft (1982). He found that many readers mistakenly say that nonwords like STEEK have a homophonic partner whereas those like FLEEK do not. It seems that STEEK activates STEAK while FLEEK does not activate FLAKE (nor FLECK). Such a result is at odds with the Dual-Route account of homophony, since the pronunciations generated by GPC rules for the nonwords STEEK and FLEEK (i.e., /sti:k/ and /fli:k/) are equally confusible with the pronunciation of a real word (STEAK, i.e., /steIk/, and FLAKE, i.e., /fleIk/, respectively) and therefore should not differ. On the other hand, STEEK will activate STEAK according to the notion of OPO Rebound, since EE will activate EA via the phoneme unit /i:/, and EEK will activate EAK via the rime unit /i:k/.2

We see then that the primary difference between the dual-route and multilevel hierarchical models is the involvement of sublexical units in the orthographic recognition system. The most recent version of the Dual-Route model (Coltheart et al., 2001) incorporates the principles of interactiveactivation into its lexical route, but does not include any sublexical level between letters and words. If it were to do so, it would become very similar to the multilevel hierarchical model (see for instance, Paap, MacDonald, Schvaneveldt \& Noel, 1987; Paap \& Noel, 1991; Paap, Noel \& Johansen, 1992); the only difference would be that grapheme-phoneme conversion would be achieved via a set of rules independent of the lexical route rather than by a grapheme/phoneme level in the same hierarchical system that includes the body/rime and morpheme levels.

The aim of the experiments to be reported here is to examine the nature of the sublexical system by manipulating the relationship between sublexical and lexical orthographic-phonological (O-P) links and seeing the effect of this on judgments made about the lexical O-P links, namely, on homophone decision responses.

The only previous examination of this, of which we are aware, is the manipulation of morphological structure undertaken by Taft (1984). In that study it was found that there was considerable difficulty in generating the 
homophonic partner of a word when the two words had differing morphological structures, though only when the task was performed silently (72\% errors). For example, it proved very difficult to elicit GOLD as a homophone of GOALED, where the former is monomorphemic while the latter includes an inflectional suffix. This result was interpreted by Taft as implying that GOALED is represented orthographically as GOAL plus ED (and phonologically as /gol/ plus /D/, where "D" denotes the past tense), while GOLD is represented as the monomorpheme GOLD (and phonologically as /gold/). Therefore, in terms of the multilevel hierarchical model, we can say that there is no OPO Rebound happening for these words at the morpheme level (nor any level below that) since GOALED and GOLD do not link to the same phonological unit (but rather to /gol/ and /gold/ respectively).

However, the conclusion that the inflected form of a word does not actually possess a representation at the whole word level, provides a way for the DualRoute model to explain Taft's data without having to introduce any sublexical levels into the lexical route. If the model accepts that there is no representation for the whole word GOALED, then it can be said that the pronunciation extracted from the lexical route might be the pronunciation of the stem only (e.g., the /gol/ of GOALED), which when fed back into the lexical system, will not gain access to the target homophone (i.e., /gold/).

Therefore, it appears that the use of homophones differing in their inflectional structure may not provide appropriate evidence for OPO Rebound at sublexical levels. Instead, what is needed are homophonic pairs of words whose sublexical representations do not suggest that they are homophonic, but where there is no involvement of affixation. Such a situation does not seem to occur in English, but it does in Korean.

Korean makes use of two types of script; an alphabetic syllabary called "hangul", and a logographic system called "hanja". Every word can be written in hangul, while nouns can usually be written in hanja as well. Words can be of one to five syllables in length, but are predominantly composed of two syllables. Each syllable is frequently a morpheme as well, in that it can usually combine with a different syllable to form a semantically-related word. When it forms a morpheme, the syllable can also often be represented by a hanja character. As in Chinese, the relationship between orthography and phonology in hanja is mostly "irregular" in the sense that subcomponents of a character do not provide a reliable guide to the pronunciation of that character. Hangul, on the other hand, is a highly regular alphabetic system, which will be described in more detail later.

As is the case in Chinese, many (phonological) syllables can be represented by more than one hanja character. For example, “部”, “不”, “父” and “夫” are all pronounced /bu:/, and are thus homophones. Words made up 
of two characters can similarly have homophonic partners. For example, “部族” and “不足” are both pronounced /bu:čok/ since “部” and “不” are both pronounced /bu:/, while “族” and “足” are both pronounced /čok/. In this example, it is clear that the homophony of the two-character words is supported by homophony at the sublexical level, that is, by the homophony of the individual characters. We will call such words "Normal Homophones". It is possible, however, to find two-character homophones whose individual characters are not themselves homophonic. This comes about when a syllable is modified after it is put together with another syllable.

Certain consonants change their pronunciation at the end of a syllable when the consonant at the beginning of the next syllable is of a particular type, and vice versa. This is called "consonant assimilation". For example, syllable-final $/ \mathrm{k} /$ changes to $/ \mathrm{r} /$ when followed by syllable-initial $/ \mathrm{m} /$, and therefore /čak/ followed by /mu:n/ creates the word /čanmu:n/. This is the same pronunciation as that which arises when the syllable /čan/ is added to /mu:n/. Because “作” is pronounced /čak/ and “長” is pronounced /čan/ (and “文” is pronounced /mu:n/), the words “作文 and “長文 are homophonic partners even though their initial characters are not themselves homophonic. There exist several other consonant combinations (e.g., $/ \mathrm{b} /+/ \mathrm{n} /, \mathrm{n} /+/ \mathrm{l} /$ ) that also become assimilated and these can all be used in creating homophonic words that include non-homophonic characters. Such words will be called "Modified Homophones". Therefore, a comparison of Normal and Modified Homophones in hanja provides an opportunity to examine the impact of nonsupportive sublexical information on judgments of whole-word homophony, and this is what Experiment 1 looks at.

\section{Experiment 1}

If the homophony of a word is determined solely on the basis of the pronunciation of the whole word, it should make no difference what the nature of its sublexical structures is. If, on the other hand, O-P links at the sublexical level influence the functioning of $\mathrm{O}-\mathrm{P}$ links at the word level, then homophone judgments will be rendered more difficult when the two levels of O-P links conflict. In other words, judgments about Normal Homophones will be easier to make than those about Modified Homophones.

The first experiment looks at this by presenting two-character Korean words in hanja script to participants who are proficient in reading this script. These participants were asked to press a "yes" or a "no" button as quickly as possible depending on whether or not they could think of another Korean word of identical pronunciation. The stimulus words either had homophonic 
targets that were Normal Homophones or Modified Homophones, or else had no homophonic partners at all.

\section{Method}

Participants. Fourteen Korean postgraduate students studying at the University of New South Wales, Australia (UNSW) participated in the experiment. They were tested individually. Given their age and educational level, it could be safely assumed that the participants were able to read the selected hanja experimental words fluently.

Materials. Eighty hanja words composed of two-characters were prepared for the experiment. Twenty of these were Normal Homophones whose individual characters were each homophonic with the individual characters of the homophonic partner. Each stimulus word had only one homophonic target, and the characters of the stimulus and target words were both different for eleven of the items, with one character the same in the other nine. Examples are “部族” (homophonic with “不足”, both being pronounced /bu:čok/), and “前後” (homophonic with “戰後”, both being pronounced /čdnhu:/).

There were also 20 words that were Modified Homophones. Examples are “人類” (homophonic with “一流”, where “人” is /in/ and “—” is /il/), and “長文” (homophonic with “作交”, where “作” is /čak/ and “長” is /čan/). Each stimulus word had only one homophonic target, and the characters of the stimulus and target words were both different for half the items, and had one character the same for the other half.

Another 40 words were included as non-homophones. The pronunciation of half of the non-homophone items involved assimilation, (e.g., “植木”, pronounced /sinmok/, where “植” is /sik/ and “木” is /mok/), while that of the other half did not (e.g., "創刊", pronounced /cangan/, where "創" is / $\breve{c}^{h}$ an/ and "FIl" is $/ \mathrm{gan} /$ ). A list of the experimental items in this and the following experiments are presented in the Appendix.

Since there were no suitable word frequency norms available for the Korean language, frequency was not controlled a priori. However, stimuli and targets that were, by intuition, thought to be frequently used were chosen. The frequencies of the words were rated approximately 6 months later by the participants on a scale of 0 (rarely seen) to 7 (frequently seen). The use of participant's ratings of the "experiential familiarity" of words has been shown to provide a reliable measure of word recognition latencies (Balota, Pilotti \& Cortese, 2001; Gernsbacher, 1984). These ratings showed that the Normal and Modified items were approximately matched on the frequency of both the presented stimulus (5.4 and 4.9 for Normal and 
Modified, respectively) and the homophonic target (5.8 and 5.9 for Normal and Modified respectively). The rated frequencies for the non-homophones were also matched between the Normal and Modified items (5.6 and 5.4, respectively).

Procedure. Words appeared on the computer monitor one by one in random order. Each item was presented for as long as it took for a response to be made, though the trial terminated if no response was made within $5 \mathrm{sec}$. There was an inter-trial interval of $500 \mathrm{msec}$, or of $800 \mathrm{msec}$ if there was no response. Participants were instructed to press a right-hand "yes" button if the word presented was pronounced identically to another word and to press a left-hand "no" button if it was not. In the instructions, they were given examples of homophones and non-homophones. They were also told not to pronounce the stimulus word aloud and to respond as quickly and as accurately as they could. Before starting the main experiment, ten items were presented for practice.

\section{Results}

The dependent variable of most interest in all the experiments to be reported will be the error rate rather than reaction time. This is because (a) it is possible that the participants will execute their response some time after they have made their initial homophone judgment because of uncertainty in the decision; (b) Taft and Chen (1992) reported error rates as high as $48 \%$ in Chinese homophone decisions which means that reaction time data for correct responses could well be based on only a small number of responses; and (c) Taft and Chen reported response times of over four seconds, a very long reaction time with considerable variability which could wash out any subtle effect that might be observed. Therefore, it will be potentially difficult to interpret reaction time data due to the fact that many variables can be thought to have an influence on it. Error rates, on the other hand, directly reflect the actual decision made and are unaffected by the above factors. Therefore, in all the experiments to be presented, the focus will be on the errors as the dependent variable, though the reaction time data will also be reported for completeness.

The results are presented in Table 1. For the analysis of errors, there was a main effect of assimilation (i.e., Modified versus Normal), $F_{\mathrm{s}}(1,13)=9.98$, $P<0.001 ; F \mathrm{i}(1,19)=4.72, P<0.005$. Analysis also showed a homophony effect, $F \mathrm{~s}(1,13)=11.97, P<0.005 ; F \mathrm{i}(1,19)=22.04, P<0.0002$, but there was no significant interaction between assimilation and homophony $(P>$ 0.10 for both $F \mathrm{~s}$ and $F \mathrm{i}$ ). For the analysis of the reaction time data, the main effect of assimilation was not shown, $F \mathrm{~s}(1,13)=3.060, P>0.10 ; F \mathrm{i}(1,19)$ 
Table 1. Error rate (\%) and mean homophone decision time (msec) for the hanja items of Experiment 1.

\begin{tabular}{lll}
\hline & Errors & R.T. \\
\hline Homophones & & \\
Normal & 40.7 & 2490 \\
Modified & 53.2 & 2696 \\
Non-homophones & & \\
$\quad$ Normal & 25.7 & 3289 \\
Modified & 30.7 & 3256 \\
\hline
\end{tabular}

$=0.62, P>0.10$, whereas there was a homophony effect, $F \mathrm{~s}(1,13)=17.64$, $P<0.002 ; F \mathrm{i}(1,19)=29.98, P<0.0003$. The interaction of assimilation and homophony was not significant, $F \mathrm{i}(1,13)=1.69,>0.10 ; F \mathrm{~s}(1,13)=2.00$, $P>0.10$.

The finding that response latencies to the homophonic words were substantially shorter than those to the non-homophonic stimuli probably reflects the difference making a positive versus a negative response. Indeed, when participants misclassified homophones as non-homophones, their response latencies were no different to those made in correctly classifying the non-homophones, both $F \mathrm{~s}<1$.

\section{Discussion}

The significant assimilation effect for homophones is the central result of this experiment: It is relatively difficult to think of the homophonic partner of a word when the pronunciation of that word is generated through consonant assimilation (i.e., the case of Modified Homophones). This suggests that the O-P relations that exist at the morpheme (or character/syllable) level play a role in determining the pronunciation of the whole word, and this is readily explained within the multilevel hierarchical framework. For Normal Homophones, OPO Rebound at the word level is supported by OPO Rebound at the sublexical morpheme level. This is depicted in Figure 3a. When “部族” is presented, activation of the homophonic partner “不足” arises not only from OPO Rebound at the whole-word level, but from activation coming up from “不” and “足” at the morpheme level, which have themselves been activated via OPO Rebound set up by the activation of “部” and “族”. The high error rate indicates that even for the normal hanja stimuli it is difficult to activate the target homophone. 
(a)

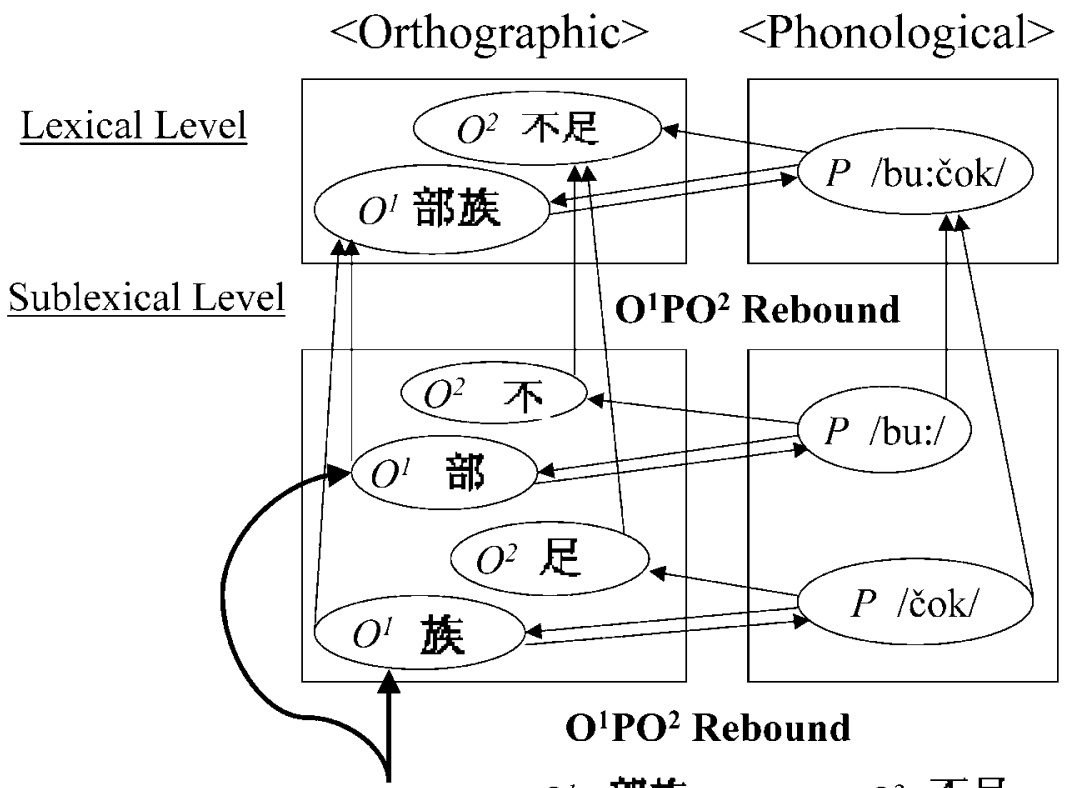

Visual stimulus $\left(O^{I}\right)$ 部族 for target $\left(O^{2}\right)$ 不尼

(b)

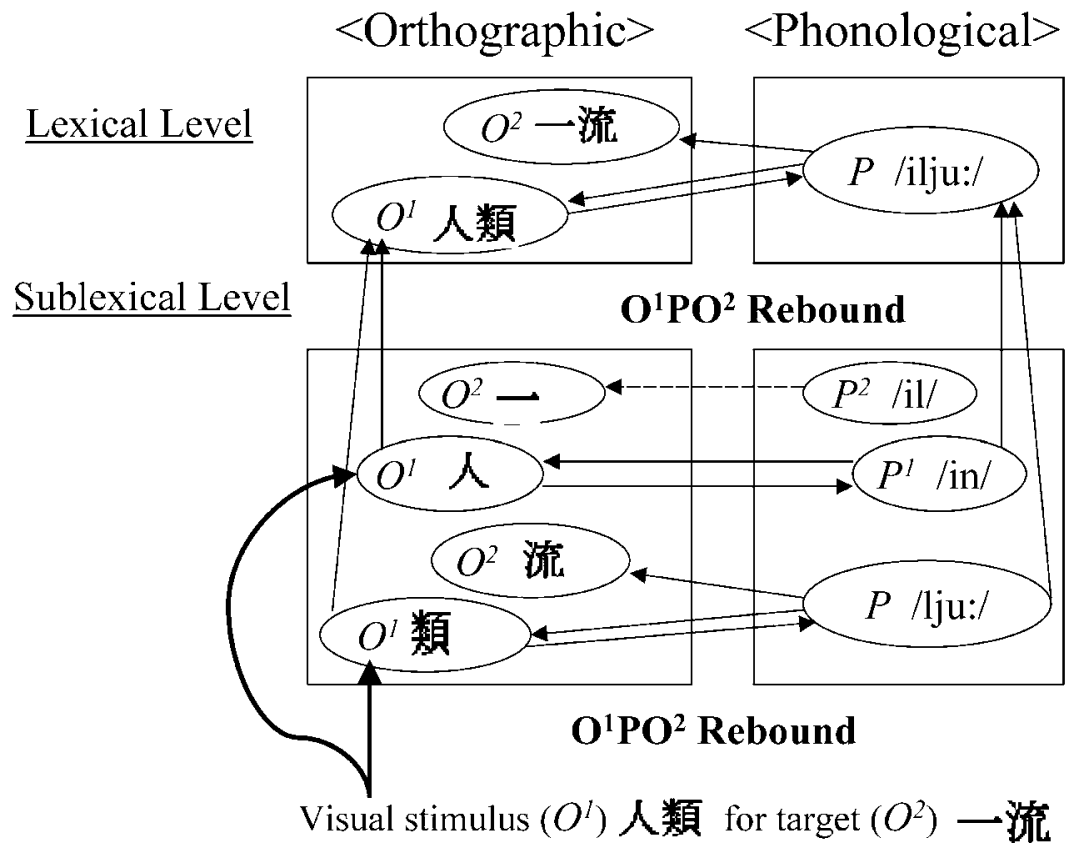

Figure 3. (a) OPO processing of Normal Homophones in hanja. (b) OPO processing of Modified Homophones in hanja. 
The situation for Modified Homophones is depicted in Figure 3b. Here the activation of “一流” when “人類” is presented arises only from OPO Rebound at the word level. The first morpheme "_." is not activated by OPO Rebound at the sublexical level since "人" and "“" are not connected to the same phonological representation. This situation makes it relatively more difficult to activate the homophonic partner of a stimulus word and hence the error rate for Modified Homophones is greater than that for Normal Homophones.

Turning to the comparison of homophone and non-homophone performance, the results are in seeming contradiction to those obtained in Chinese by Taft and Chen (1992). In that study, it was relatively difficult to make a "no" response whereas in the present experiment, the reverse was true.

In the Taft and Chen experiment, however, the items were single characters, which in Chinese can potentially have many homophonic partners. It is very difficult to be sure that no homophonic partner exists for a single Chinese character since, if it does, it might be in no way orthographically similar to it. We can clarify this by contrasting it to the situation in English, where sublexical information can be used to establish what the potential homophonic candidates are. For example, one knows that if YEAR had a homophonic partner, it would likely be YEER, YERE or YIER. In other words, for English non-homophones, OPO Rebound is successful at the sublexical level, but when the information activated at this level fails to produce activation at the word level (e.g., Y + EER), a "no" decision is facilitated. With Chinese characters, on the other hand, there is no sublexical influence on the "no" decision. Additionally, one is biased toward making a "yes" response in Chinese since homophony is so common. Therefore, the error rate in non-homophone performance with single Chinese characters is high. In the present experiment, the words have two characters and this provides an additional level on which to base the decision (character and whole-word levels), but also the amount of homophony amongst twocharacter words is considerably lower than that amongst single characters, and therefore the bias to say "yes" is reduced.

It seems then that the results of Experiment 1 require the involvement of phonological activation of sublexical units that are smaller than the word, but larger than the grapheme; in this case, morphemes (or syllables). However, it could be argued that phonological activation at the morpheme level is only relevant to the processing of a logographic script like hanja which has no graphemes and is morphologically based, and that in an alphabetic script, the only sublexical O-P links that exist are those between graphemes and phonemes. The Korean language again allows a test of this claim since an alphabetic orthographic system also exists, namely hangul. Modified Homophones can be created in hangul in the same way as in hanja, so 
lexical/sublexical incompatibility can again be examined and this is undertaken in Experiment 2. Once more, if the homophony of a word is determined solely on its whole-word pronunciation then the nature of its sublexical structure should not matter. If, on the other hand, O-P sublexical links influence $\mathrm{O}-\mathrm{P}$ lexical ones then homophone judgments will be difficult when the two levels conflict.

\section{Experiment 2}

Hangul has 14 consonants and 10 vowels. Every orthographic syllable is composed of either a CV (consonant plus vowel), or CVC. Letters are organized within a syllable in a vertical structure (e.g., $\bar{c} / \mathrm{h} /+\mathrm{r} / \mathrm{d} /+\mathrm{L} / \mathrm{n} /=$ 한 $/ \mathrm{han} / ; / \mathrm{k} /+\neg / \mathrm{u}: /+\mathrm{T} / \mathrm{k} /=$ 국 $/ \mathrm{ku}: \mathrm{k} /$ ), as well as being horizontal from syllable to syllable (e.g., "한국" =/hanku:k/). Thus, vowels are placed in orthographic syllables either at the right side of or below the initial consonant. The last consonant is always placed under this structure of initial consonant plus vowel. A vowel hardly ever changes its pronunciation no matter what its consonantal context, and every consonant is sounded, except for " $\varnothing$ " in initial position (pronounced $/ \mathrm{n} /$ in final position).

When words undergo consonant assimilation, the spelling in hangul maintains the unassimilated form. For example, /čak/ is spelled "작", and when "문" (/mu:n/) is added, the resulting word is spelled "작문" but pronounced /čanmu:n/. Therefore, “작문" and “장문” (where “장” is pronounced /čan/) are homophones.

There is a second way in which homophones can be created in Korean, also through modifications made when two syllables are placed together, namely, "boundary-change". This occurs when the first syllable has a final consonant (except " $\varnothing$ ") and the second syllable begins with the silent initial consonant. For example, when "착" / $\mathrm{c}^{\mathrm{h}} \mathrm{ak} /$ is followed by "오" /o/, it has the pronunciation / $\check{c}^{\mathrm{h}} \mathrm{ako} /$, and this is the same as when "차" / $\mathrm{c}^{\mathrm{h}} \mathrm{\alpha} /$ is followed by “고" /ko/. Again we see how two words can be homophonic, like "착오" and “차고” which are both pronounced / $/ \mathrm{c}^{\mathrm{h}} \mathrm{ako} /$, despite the fact that their orthographic syllables are not homophonic on their own. Boundary-change also produces homophones in hanja, but these were not used in Experiment 1.

Now, although it is possible to create Modified Homophones in hangul via consonant assimilation and boundary-change, it is impossible to create Normal Homophones to compare them to. Two words that are Normal Homophonic partners in hanja are always written in the same way in hangul. It is possible, though, to compare the absolute level of performance with hangul Modified Homophones to that obtained with hanja in Experiment 1 and thereby determine the comparable degree of difficulty of the judgments. 
Table 2. Error rate (\%) and mean homophone decision time (msec) for the hangul items of Experiment 2.

\begin{tabular}{lll}
\hline & Errors & R.T. \\
\hline Homophones & 52.1 & 2531 \\
Non-homophones & 21.4 & 2817 \\
\hline
\end{tabular}

\section{Method}

Participants. Fourteen Korean postgraduate students studying at UNSW were tested individually. About half of the participants were the same as those in Experiment 1. Although this experiment is reported here as Experiment 2, it was actually carried out 6 months prior to Experiment 1 .

Materials. There were two different conditions, homophones and nonhomophones. In the homophone conditions, there were 20 stimuli created either by consonant assimilation or by boundary-change, though mostly the former (e.g., “작문"/“장문”, “착오”/“차고”). None of the words chosen were ambiguous, in the sense of there being another word spelled the same but meaning something different. The non-homophone conditions comprised twenty non-homophone words (e.g., "논리”, “묵례”, “반엉”).

Frequency control of the stimuli and their targets was the same as in Experiment 1. The frequency of the homophone cases was 5.2 and 5.6 for the stimuli and targets respectively, and 5.6 for the non-homophones.

Procedure. The procedure was the same as in Experiment 1.

Results

The results are presented in Table 2. Analysis of errors revealed that the difference between the homophone and the non-homophone conditions was significant, $F \mathrm{~s}(1,13)=10.80, P<0.05 ; F \mathrm{i}(1,19)=34.09, P<0.01$, with the homophones being associated with more errors than the non-homophones.

For the analysis of the reaction time data, the difference between the homophone condition and the non-homophone condition was marginal for participants, $F \mathrm{~s}(1,13)=3.73, P=0.07$, but was significant by items, $F \mathrm{i}(1,19)$ $=6.41, P<0.05$ A comparison of the errors made for the Modified Homophones in Experiments 1 and 2 revealed no sign of a difference, $F \mathrm{i}<1$. 


\section{Discussion}

The first thing that can be noted about the outcome of this experiment is that performance on Modified Homophones appears to be the same regardless of script. That is, the error rates obtained for the modified homophones presented in hangul are highly comparable to the error rates obtained in Experiment 1 for the Modified Homophones presented in hanja. In both cases the error rate was a little worse than $50 \%$. This suggests that O-P links at the level of the morpheme (or syllable) play a role in determining the O-P relationships at the level of the word even in an alphabetic script. In regard to the error rates, it is worth also pointing out that rates near 50\% do not mean that participants were guessing, since in both Experiment 1 and 2 the error rates for the non-homophonic items were far from chance.

As outlined earlier, OPO Rebound provides a useful framework in which the influence of sub-lexical O-P links can be considered. In OPO Rebound, when a stimulus word has a homophonic partner, activation passes from the phonological representation of the stimulus word to the orthographic representation of the target word. However, activation will also pass back to the orthographic representation of the stimulus word, and therefore, there will actually be competition between the stimulus and the target.

Furthermore, in the modified homophone case, not all of the components of the target word will be activated by OPO Rebound at the sublexical level (see Figure 4). Thus it will be relatively difficult to activate the homophonic partner relative to the stimulus itself and hence the error rate for Modified Homophones will be greater than that for Normal Homophones.

It should be pointed out, however, that in hangul, homophone decisions could be made without recourse to OPO Rebound. This is because it is possible to know what the homophonic partner of a word is likely to be if it exists. For example, it can be known that the only way that "작문" can be a homophone is through consonant assimilation, and this assimilation rule can then be applied to determine if it produces a word or not by seeing if it matches with any orthographic word-level representation. Thus OPO Rebound could be circumvented. It may be, then, that the effect of stimulustarget relationship arises from some strategy adopted in addition to OPO Rebound. If so, we have to be aware of the possibility that the homophone decision task is open to strategies that are specific to performance in that task. Nevertheless, if such strategies are useful in performing the task, they will have something to tell us about how the orthographic-phonological system is set up. That is, a strategy will only be worth applying if the information that it draws upon is readily accessible and this tells us that the system is set up in such a way that makes that information accessible in a task that is rarely encountered in the normal use of the system. 


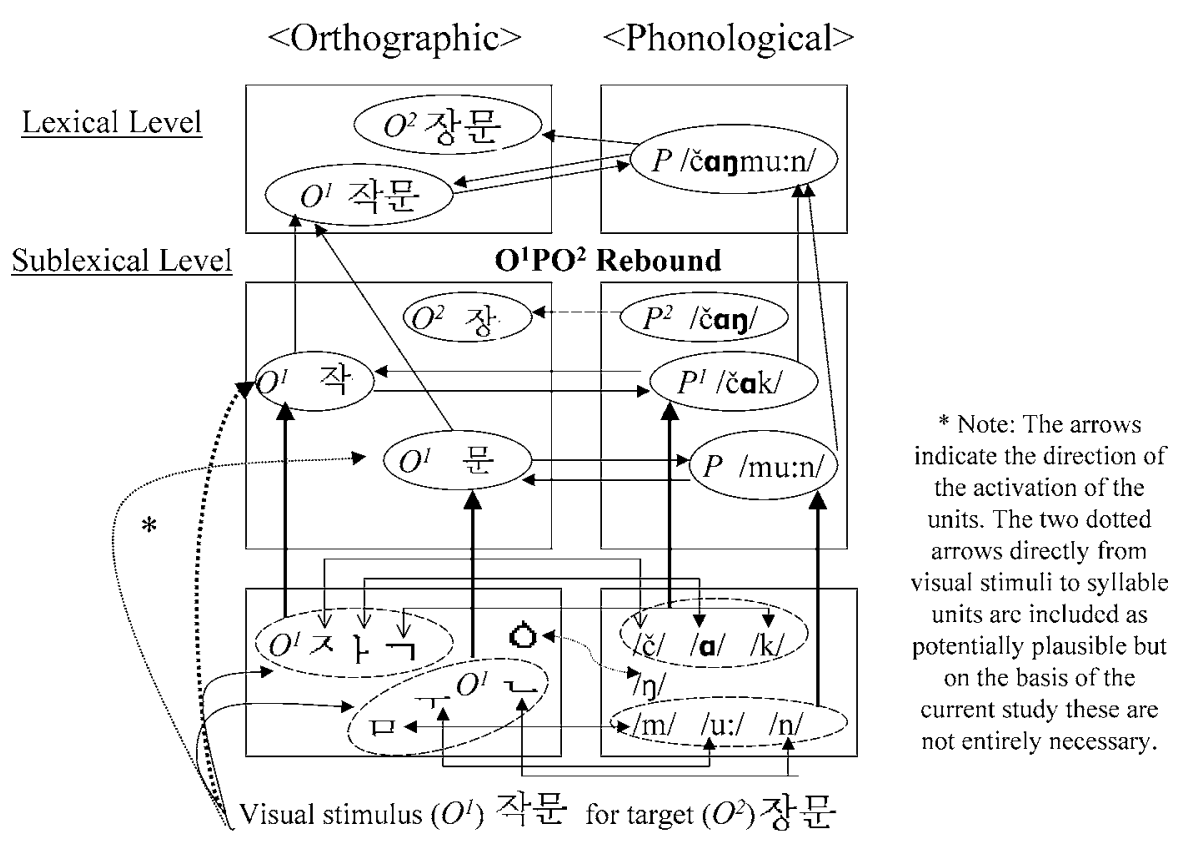

Figure 4. OPO Processing of Modified Homophones in hangul.

There are, however, several difficulties in the suggestion that an orthographic conversion strategy can explain the overall pattern of results. First, an orthographic conversion strategy is not possible in nonalphabetic hanja and, therefore, the results obtained in Experiment 1 would still need explanation. Second, the finding that a homophone judgment is particularly difficult to make under certain conditions (e.g., with modified homophones) suggests that task-specific strategies are not involved. A strategy will presumably only be adopted if it is going to enhance performance in the task, so it is hard to see how a task-specific strategy can account for the central point that the homophony of Modified Homophones is particularly difficult to detect.

How might the Dual-Route Model account for these findings? According to the standard model, O-P links occur only at the word level (the lexical route to pronunciation) and between graphemes and phonemes (the non-lexical route). As pointed out earlier, homophone decisions must be made by reentering the lexical system via the pronunciation that was generated for the stimulus either lexically if the stimulus was a word, or non-lexically if it was a nonword. If a different word to the stimulus is so accessed, then a positive homophone decision can be made. This procedure is functionally equivalent to OPO Rebound and, if the stimulus word is inadvertently re-accessed instead of its homophonic partner, the equivalent of OPO Competition 
can occur. However, given that there is no involvement of orthographicphonological links at the sublexical level, how does one account for the effect of incompatible sublexical information within the Dual-Route framework? If there is no sublexical information to support the lexical level, why do Normal Homophones differ from Modified Homophones?

The Dual-Route explanation for this must be given at the graphemic level of analysis since this is the only sublexical information available to the system. But is it possible to explain all of the sublexical effects in terms of graphemic analysis? Take “작문” and “장문” (both pronounced /čanmu:n/, but " 7 " is $/ \mathrm{k} /$ and " $\mathrm{O}$ " is $/ \mathrm{y} /$ ). A contrast between these two hangul words could emerge from grapheme-phoneme conversion because of the difference in pronunciation of the graphemes " $\neg$ " and " $O$ ". However, even without considering how this might lead to difficulties in making the judgment of homophony, two major problems seem to militate against a grapheme-level explanation. First, the effect of lexical/sublexical incompatibility obtained in hanja cannot be explained since there can be no grapheme-phoneme conversion in a logographic script: It would have to be argued that the system for processing logographic script is entirely different from that used for alphabetic script and the effect for Modified Homophones arises from different sources in the two scripts, but is coincidentally of the same magnitude. Second, it is hard to see how the DRC model can capture assimilation in a manner that would generate difficulties in determining the status of modified homophones. One possibility is that inhibition may be generated between the whole-word pronunciation and that produced via grapheme to phoneme conversion. However, this would require that assimilation does not occur at the level of grapheme to phoneme conversion and if this were the case then it should be that nonwords that are homophonic to words via assimilation would never be recognised as such. In order to constrain the options available to dual route models for explaining why homophone decisions with modified homophones are difficult to make, it is necessary to establish whether assimilation can occur at the grapheme/phoneme level. This can be determined by ascertaining whether nonwords can be judged as homophonic with words through assimilation.

\section{Experiment 3}

Pseudohomophones are nonwords that are homophonic with real words (e.g., McCann, Besner \& Davelaar, 1988; Taft, 1982). Whereas the DRC model incorporates a special nonlexical processor, the multilevel hierarchical model does not. Thus, under the multilevel account, pseudohomophones will be processed the same way homophones, except that since such items do not 
have a word-level representation their phonological representation will have to be constructed from sublexical O-P links and then homophony determined from the fact that OPO Rebound activates a word-level representation to threshold. Further, since nonwords do not have representations at the wholeword level there will be no competition between the stimulus and target units (i.e., no OPO Competition, at least at the whole-word level), therefore, the error rate for pseudohomophones should be lower than the Modified Homophones in Experiment 1 and 2.

The following experiment, then, will determine if assimilated pseudohomophones are indeed considered to be homophonic and whether making homophone decisions on these stimuli is relatively easier than with word stimuli. To avoid any systematic relationship between pseudohomophones and their target words, pseudohomophones were constructed by applying an assimilation rule in two ways, one where the first syllable of the pseudohomophone was the same as that of the homophonic target while the second syllable differed (e.g., "밀 님" $/ \mathrm{mil} /+/ \mathrm{nim} /$, homophonic with the real word, "밀 림" $/ \mathrm{mil} /+/ \mathrm{lim} /$ ) and the other where it was the second syllable which was kept intact (e.g., "삭류" /sak/+/lju/, homophonic with the real word, "상류" /san/+/lju/). There is no reason to expect any difference between these two types of pseudohomophones, but they were looked at separately in this experiment since half of the items were of one sort and half of the other.

\section{Method}

Participants. Participants were the same as in Experiment 1 and were tested individually (approximately three months later).

Materials. Forty bisyllabic nonwords were constructed for the pseudohomophone task and half of them were pseudohomophones and half were not. The assimilated pseudohomophones were subcategorized into two conditions, one having an intact syllable in the first position of the homophonic word (e.g., "밀남") and the other in the second position of the homophonic word (e.g., "삭류"). The non-homophones were nonwords that could undergo assimilation, but for which that assimilated form did not exist as a real word (e.g., "엄 놕'). Since in the homophone condition the stimulus items were orthographic neighbours of the targets, the non-homophones items were constructed so that the vast majority of them were only a single letter different from a word. Furthermore, in order to make it less likely for participants to adopt a particular strategy in making homophone decisions, 40 filler items were included that could potentially have homophonic partners via boundary change but not assimilation (half were homophonic with words). 
Table 3. Error rate (\%) and mean homophone decision time (msec) for the hangul nonwords items of Experiment 3.

\begin{tabular}{lll}
\hline & Errors & R.T. \\
\hline Pseudohomophones & & \\
First syllable intact & 11.4 & 1291 \\
Second syllable intact & 16.6 & 1292 \\
Non-pseudohomophones & 25.4 & 2107 \\
\hline
\end{tabular}

Procedure. The pseudohomophone decision task was basically the same as the homophone decision task as used in the previously described experiments. Participants were told that all items presented were nonwords and instructed to give a "yes" response if there was a word pronounced in exactly the same way as the item presented, and "no" if there was not. The rest of the instructions and procedure were the same as for the homophone decision task.

Results

Table 3 shows the results. There was no significant difference on errors between the two pseudohomophone conditions on either the subject or item analysis, $F \mathrm{~s}(1,13)=1.578, P>0.05 ; F \mathrm{i}(1,9)=1.40, P>005$. There was however, a difference between the combined error rate of these conditions and the non-homophone condition for subjects, though not for items, $F \mathrm{~s}(1,27)$ $=5.366, P<0.05 ; F \mathrm{i}(1,19)=2.691, P>0.05$. Looking at reaction times, the main effect of homophony was revealed between the combined pseudohomophone conditions and the non-homophone condition, $F \mathrm{~s}(1,13)=32.27$, $P<0.002 ; F \mathrm{i}(1,19)=104.85, P<0.001$ with the non-homophones being associated with longer response time than the homophones. No other effect was significant $(P>0.10)$.

A comparison of the error rate of the pseudohomophone conditions of this experiment (the average of two pseudohomphone conditions) with the homophones of Experiment 2 revealed a significant difference, $F \mathrm{~s}(1,26)=$ 7.238, $P<0.001, F \mathrm{i}(1,28)=4.144, P<0.01$.

\section{Discussion}

The results of Experiment 3 are clear-cut. The homophony of a nonword item is more easily detected than the homophony of the equivalent word item (Homophones in Experiment 2). Such a result strongly supports the notion 
of OPO Competition whereby recognition of the target is inhibited when the orthographic representation of the stimulus item is re-activated during OPO Rebound. The relative ease of responding to pseudohomophones arises from the fact that the stimulus does not have an orthographic representation at the whole-word level and, therefore, there can be no OPO Competition.

The current result also indicates that assimilated pronunciations of the stimuli were equivalent to their target pronunciations. This finding bears on the interpretation of the findings of Experiment 1 and 2. That is, it might be suggested that the pronunciation of normal homophones are more similar to each other than are the modified ones (as the latter contain different phonological components, e.g., /k/ in /čak/+/mu:n/ and $/ \mathrm{n} /$ in $/ \mathrm{ccon} /+/ \mathrm{mu}: \mathrm{n} /$ ). Given this, the error rate difference between the two types might simply reflect a difference in the degree of homophony and not one resulting from sublexical processing. However, the finding that participants had relatively little difficulty in judging the homophony of modified homophones indicates that any difficulty with the modified homophones of the previous experiments has nothing to do with their degree of homophony. In order to make a pseudohomophone decision, it is proposed that a phonological representation is constructed on the basis of the syllables (and/or graphemes) of the presented nonword, along with consonant assimilation if relevant, and this representation is then activated at the phonological whole-word level. When an orthographic representation is then activated via this phonological one, the target word can be recognized. In fact, pseudohomophone decision responses can potentially be made even more easily than this, namely, in response to the mere presence of a phonological representation. Activating the orthographic representation of the word is unnecessary since the existence of a phonological representation is itself proof enough that there is a word homophonic with the nonword.

Whether OPO Rebound is or is not actually used with pseudohomophones is not important. What is important is that for Homophones, OPO Rebound is required and hence they encounter the debilitating effects of OPO Competition leading to a marked increase in error rate. This contrasts with pseudohomophones where OPO Competition does not occur, either because the orthographic representation of the target is not engaged in making the response or because it is engaged, but does not encounter competition from an orthographic representation of the stimulus.

For the pseudohomophone stimuli, the position of the syllable that was shared with the target word had no impact on performance, and there is no reason to suppose that it should have. A hangul nonword will activate syllable-level representations, if they exist, and these will feed their activation up to the word level. Thus a syllable shared by the pseudohomophone and its 
target word will activate the target word to some extent, but it should make no difference whether that syllable is in first or second position.

\section{General discussion}

The experiments reported here point to a number of characteristics of the links that exist between orthography and phonology in lexical memory. It is demonstrated that such links can be found not just between word-level units or between graphemes and phonemes, but between sublexical units as well. These units may be morphemes or syllables or both. Such a conclusion is based on the finding that when O-P links at the sublexical level do not correspond with O-P links at the word level (i.e., in the case of Modified Homophones), homophone decisions become relatively difficult to make. The judgment of homophony must ultimately be based on O-P links at the word-level, so the detrimental effect of sublexical incompatibility must mean that the sublexical O-P links play a role in determining word level O-P links.

Such a situation naturally falls out of the multilevel hierarchical model because activation is automatically passing up to the word level via any sublexical levels that exist for the particular script. Homophony is determined on the basis of activation passing from the orthographic representation of the stimulus to its equivalent phonological representation and then back to the orthographic representation of the target (OPO Rebound). For the typical homophone (i.e., Normal Homophones in hanja), OPO Rebound occurs at all sublexical levels and corresponds to the OPO Rebound occurring at the word level. On the other hand, for Modified Homophones in both a logographic script (as with hanja) and an alphabetic script (as with hangul), there is no suggestion at the sublexical levels that the stimulus is homophonic with the target. This influence of sublexical information in the processing of a word explains the advantage in responding to Normal Homophones compared to Modified Homophones.

How might a dual route model explain these results? The results of Experiment 3 , in which nonwords were perceived as homophonic to words via consonant assimilation, suggests that the nonlexical route is able to produce assimilated pronunciations. It is possible that assimilation could be captured by GPC rules in the model if they were position-sensitive (as are those proposed by Coltheart et al., 1993). However, if this were the case, the difference between the Normal vs Modified homophones could not be explained simply as a conflict between rule-based and whole-word pronunciations. To produce conflicting pronunciations, it seems necessary for the Dual-Route model to introduce a level of analysis into the system that involves sublexical 
units larger than the grapheme, that is, syllable and/or morpheme units. If this level is introduced into the non-lexical route, it would have to take the form of whole syllables being associated with their pronunciation, and these would have to have an opportunity to come into play when the stimuli were words (presumably when the response takes a long time to make, as with homophone judgments). However, the simplicity of a GPC system would then be lost because the representation of each syllable in a non-lexical route would be almost entirely redundant. The only additional information it could possibly provide in hangul would be the different pronunciations of a letter at the beginning and end of a syllable. It seems, then, that the required sublexical level must be introduced into the lexical route rather than the non-lexical route, but in so doing, the lexical system would become indistinguishable from the multilevel hierarchical account.

Therefore, we see that the homophone decision paradigm using Korean materials has been useful in elucidating the nature of the lexical processing system. The results point to the requirement that there be activation of sublexical orthographic units larger than the grapheme, with these units being linked to their phonology.

Whether the sublexical units referred to here represent syllables or morphemes is an issue on which we have had to remain neutral. In the items included in the present study, there was a mixture of cases where either the syllable was also a morpheme or it was not. The only way to examine which unit is the relevant one would be to specifically find Modified Homophones which were bisyllabic but monomorphemic. If these were easier to respond to as homophones than the bimorphemic Modified Homophones predominantly used here, it would imply that it is the morpheme and not the syllable that is important. On the other hand, if the two types of Modified Homophones show the same pattern of responses, it would imply that the syllable is represented in the system, though whether morphemes are represented as well would remain an open question (since monosyllabic bimorphemic words do not exist to be tested).

The issue of whether representation depends on morphemic or syllabic structure might actually turn out to be inconsequential. As mentioned earlier, the term "morpheme" is being used here to mean "morphemic form" in the sense that homophonic morphemes are represented as a single unit in the phonological system rather than as two. ${ }^{3}$ As such, the only difference between a unit representing a morpheme and one representing a syllable is that the former would have links to the semantic system while the latter would not (see Taft, Liu \& Zhu, 1999, for a more detailed analysis of the implications of this approach). 
Another issue that can be raised is the nature of the word-level phonological representation. We have been describing that representation as being akin to the phonetic or surface form of the word. Alternatively, though, the representation could be of an underlying abstract form that incorporates morphological (or syllabic) structure (see for example, Chomsky \& Halle, 1968) or one that is influenced by the orthography of the word (e.g., Taft \& Hambly, 1985). In this way, the phonological representation for the two forms of a Modified Homophone will differ (e.g., /čak/mu:n/ and /čan/mu:n/), making it difficult to judge homophony. In order to make a correct response, the surface form must be constructed from the underlying form of the stimulus item and then fed into the speech recognition system (either vocally or subvocally). Again, however, it must be determined that any word so accessed is different from the stimulus item, and this must be based on orthographic information rather than purely semantic information or else the problem with homographs (like PORT) will arise.

While this is an alternative way of conceptualizing the system, it is functionally equivalent to the framework we have been using. In the multilevel hierarchical account, the sublexical levels represent the abstract underlying representations while the whole-word level represents the surface form. In both conceptualizations, there is a flow of activation from the orthographic representation of the stimulus to a surface form and back to the orthographic representation of the target (i.e., OPO Rebound) and also, the underlying representation is activated in the course of activating the surface form. Regardless of which framework one adopts, the central point remains that sublexical information has an impact on the whole-word phonological representation in lexical memory, a fact that is often missing from considerations of the phonological representations that are accessed during the reading process (as, for example, in the Dual-Route model).

Although the previous discussion made mention of the flow of activation from a surface form back to the orthographic representation of the target (and the underlying sublexical representations) in none of the figures depicting the model (Figures 3a, b and 4) have we included top-down feedback from word to syllable representations. The role of top-down feedback might be useful in understanding the details of how homophone decisions might be made on different types of modified homophone. That is, with modified homophones, the pronunciation of one member of the pair typically undergoes more modification (via assimilation) than the other. Since this modification results in inconsistency between the word-level and sublexical-level pronunciations, we call this more modified member the "inconsistent" type (and the less modified one "consistent"). For instance, half of the modified homophone stimuli 
presented in Experiment 2 can be categorized as the consistent type (“장문" $/ \check{c} a n /+/ m u: n /)$ because their whole word pronunciation (e.g. /čanmu:n/) is consistent with the pronunciation of their sublexical elements (/čan/, /mu:n/ activated by the stimuli at the sublexical level, “장”, “문"). The other half of the presented stimuli were the inconsistent type ("작문" /čak/+/mu:n/) because their whole word pronunciation (e.g. /čanmu:n/) was inconsistent with the sublexical pronunciation (/čak/, /mu:n/ activated by the stimuli). Given this difference in the stimuli, an OPO Rebound model that includes top-down links between word and syllable representations might predict that it would be easier to make a homophone decision when presented with inconsistent stimuli compared to the consistent ones. This is because an inconsistent stimulus word (e.g., "작문" /čak/+/mu:n/) will activate a phonological wordlevel representation (e.g., /čanmu:n/) that will then activate the component phonological syllables (/čan/,/mu:n/) and then the orthographic ones ("장", “문”), which will in turn support the activation of the target (“장문") at the lexical level. Such will not be the case when the stimulus presented is of the consistent type, as the top-down process will lead to activation of the same sublexical elements that have already been activated by the stimulus.

When the data of Experiment 2 were reanalysed in terms of consistent vs. inconsistent stimulus types, it turned out that there were indeed fewer errors made for the inconsistent stimuli compared to when consistent ones (36\% vs. $64 \%$ errors, respectively). However, although the above top-down account is compatible with the pattern of the reanalysis, we are hesitant to make too much of this because the processing of the consistent and inconsistent modified forms may have been confounded by word frequency differences. That is, the inconsistent stimuli typically were lower in frequency than their targets whereas this was not the case for the consistent ones. Nevertheless, the idea of top-down feedback is certainly worth investigating in a more systematic fashion in a future study.

Finally, we need to consider the question of whether the conclusions drawn from results obtained in one language can be generalized to other languages. Is it the case that the results obtained in hangul say nothing about the processing of other alphabetically scripted languages, and that the results obtained in hanja say nothing about lexical processing systems in general? Certainly it could be argued that the processing of logographic script, like hanja, engages very different mechanisms to those involved in alphabetic script, but the parallels obtained here between hanja and hangul suggest that the homophone decision task, at least, is not sensitive to script differences. Within the framework being adopted here, the primary difference being proposed between hanja and hangul is in the nature of the sublexical levels 
that must be passed through in order to activate the word representation. In hanja, phonology can only be associated with the syllable/morpheme (i.e., character) level and the word level, while in hangul, it can be associated with the letter level as well.

It is also conceivable that hangul is processed in a qualitatively different manner to other alphabetic scripts as a result of the physical organization of graphemes into syllables. Perhaps the syllable/morpheme only assumes importance as a sublexical unit when it forms a physically discrete graphemic unit. Such an idea, however, is not supported by the fact that the bulk of research which favors morphemic and/or syllabic processing is based on alphabetic scripts, like English, where there is no such physical structuring of the word (e.g, Burani, Salmaso \& Caramazza, 1984; Fowler, Napps \& Feldman, 1985; Pillon, 1998; Taft, 1979, 1981; Taft \& Forster, 1975). It may well be the case that the syllable assumes greater importance in a script like Korean than one like English (whereas the body may assume greater importance in English than Korean), but this does not mean that fundamentally different processing mechanisms are involved in the different languages: It may simply reflect the nature of the sublexical units that are relevant to processing that particular script.

\section{Notes}

1. A grapheme is a letter or letter cluster that represents a single phoneme (Henderson, 1982).

2. Taft (1982) invoked the notion of Grapheme-Grapheme Conversion Rules (GGC Rules) to explain his data. These are functionally equivalent to OPO Rebound at the grapheme/ phoneme level since they provide a way of "converting" EE to EA.

3. In the same way, the term "word" actually refers to "word form" because homophonic words (like “차고” and “착 오”) have a single phonological representation /čako/.

\section{References}

Balota, D.A., Pilotti, M. \& Cortese, M.J. (2001). Subjective frequency estimates for 2,938 monosyllabic words. Memory and Cognition, 29, 639-647.

Besner, D., Twilley, L., McCann, R.S. \& Seergobin, K. (1990). On the connection between connectionism and data: Are a few words necessary? Psychological Review, 97, 432-446.

Bowey, J.A. (1990). Orthographic onsets and rimes as functional reading units. Memory and Cognition, 18, 419-427.

Burani, C., Salmaso, D. \& Caramazza, A. (1984). Morphological structure and lexical access. Visible Language, 18, 342-352.

Chomsky, N. \& Halle, M. (1968). The sound pattern of English. New York: Harper \& Row. 
Coltheart, M. (1980). Reading, phonological recoding and deep dyslexia. In M. Coltheart, K.E. Patterson \& J.C. Marshall (Eds.), Deep dyslexia (pp. 197-226). London: Routledge \& Kegan Paul.

Coltheart, M., Davelaar, E., Jonasson, J.T. \& Besner, D. (1977). Access to the internal lexicon. In S. Dornic (Ed.), Attention and performance IV (pp. 535-555). Hillsdale, New Jersey: Lawrence Erlbaum Associates.

Coltheart, M., Curtis, B., Atkins, P. \& Haller, M. (1993). Models of reading aloud: Dual-route and parallel-distributed-processing approaches. Psychological Review, 100, 589-608.

Coltheart, M., Rastle, K., Perry, C., Langdon, R. \& Ziegler, J. (2001). DRC: A dual route cascaded model of visual word recognition and reading aloud. Psychological Review, 108, 204-256.

Dell, G.S. (1986). A spreading activation theory of retrieval in sentence production. Psychological Review, 93, 283-321.

Drews, E. \& Zwitserlood, P. (1995). Morphological and orthographic similarity in visual word recognition. Journal of Experimental Psychology: Human Perception and Performance, $21,1098-1116$.

Fowler, C.A., Napps, S.E. \& Feldman, L. (1985). Relations between regular and irregular morphologically related words in the lexicon as revealed by repetition priming. Memory and Cognition, 13, 241-255.

Glushko, R.J. (1979). The organization and activation of orthographic knowledge in reading aloud. Journal of Experimental Psychology: Human Perception and Performance, 3, 674691.

Gernsbacher, M.A. (1984). Resolving twenty years of inconsistent interactions between lexical familiarity and orthography, concreteness, and polysemy. Journal of Experimental Psychology: General, 113, 256-281.

Henderson, L. (1982). Orthography and word recognition in reading. New York: Academic Press.

Humphreys, G.W. \& Evett, L.S. (1985). Are there independent lexical and nonlexical routes in word processing? An evaluation of the dual route theory of reading. Behavioral and Brain Sciences, 8, 689-740.

Kay, J. \& Bishop, D. (1987). Anatomical differences between nose, palm, and foot, or, the boy in question: Further dissection of the processes of sublexical spelling-sound translation. In M. Coltheart (Ed.), Attention and performance XII: The psychology of reading (pp. 449469). Hillsdale, New Jersey: Lawrence Erlbaum Associates.

McCann, R.S., Besner, D. \& Davelaar, E. (1988). Word recognition and identification: Do word-frequency effects reflect lexical access? Journal of Experimental Psychology: Human, Perception and Performance, 14, 693-706.

McClelland, J.L. (1987). The case for interactionism in language processing. In M. Coltheart (Ed.), Attention and performance XII: The psychology of reading (pp. 1-36). Hillsdale, New Jersey: Lawrence Erlbaum Associates.

McClelland, J.L. \& Rumelhart, D.E. (1981). An interactive activation model of context effects in letter perception: Part 1. An account of basic findings. Psychological Review, 88, 375407.

Paap, K.R. \& Noel, R.W. (1991). Dual-route models of print to sound: Still a good horse to race. Psychological Research, 15, 13-24.

Paap, K.R., McDonald, J.E., Schvaneveldt, R.W. \& Noel, R.W. (1987). Frequency and pronounceability in visually presented naming and lexical decision tasks. In M. Coltheart (Ed.), Attention and performance XII: The psychology of reading (pp. 221-243). Hillsdale, New Jersey: Lawrence Erlbaum Associates. 
Paap, K., Noel, R. \& Johansen, L. (1992). Dual route models of print to sound: Red herrings and real horses. In R. Frost \& L. Katz (Eds.), Orthography, morphology, and meaning. Advances in psychology (pp. 293-318). Amsterdam: North-Holland.

Pillon, A. (1998). The pseudoprefixation effect in visual word recognition: A true - Neither strategic nor orthographic - morphemic effect. Quarterly Journal of Experimental Psychology, 51, 85-120.

Plaut, D.C. (1997). Structure and function in the lexical system: Insights from distributed models of word reading and lexical decision. Language and Cognitive Processes, 12, 767808.

Plaut, D.C., McClelland, J.L., Seidenberg, M.S. \& Patterson, K.E. (1996). Understanding normal and disordered reading: Computational principles in quasi-regular domains. Psychological Review, 103, 56-115.

Rastle, K., Davis, M., Marslen-Wilson, W.D. \& Tyler, L.K. (2000). Morphological and semantic effects in visual word recognition: A time-course study. Language and Cognitive Processes, 5, 507-537.

Rumelhart, D.E. \& McClelland, J.L. (1982). An interactive activation model of context effects in letter perception: Part 2. Psychological Review, 89, 60-94.

Seidenberg, M.S. \& McClelland, J.L. (1989). A distributed, developmental model of word recognition and naming. Psychological Review, 96, 523-568.

Stolz, J.A. \& Besner, D. (1998). Levels of representation in visual word recognition: A dissociation between morphological and semantic processing. Journal of Experimental Psychology: Human Perception and Performance, 24, 1642-1655.

Stone, G.O., Vanhoy, M. \& Van Orden, G.C. (1997). Perception is a two-way street - feedforward and feedback phonology in visual word recognition. Journal of Memory and Language, 36, 337-359.

Taft, M. (1979). Recognition of affixed words and the word frequency effect. Memory and Cognition, 7, 263-272.

Taft, M. (1981). Prefix stripping revisited. Journal of Verbal Learning and Verbal Behaviour, 20, 289-297.

Taft, M. (1982). An alternative to grapheme-phoneme conversion rules? Memory and Cognition, 10, 465-474.

Taft, M. (1984). Evidence for an abstract lexical representation of word structure. Memory and Cognition, 12, 264-269.

Taft, M. (1991). Reading and the mental lexicon. Hove, UK: Lawrence Erlbaum Associates.

Taft, M. (1994). Interactive-activation as a framework for understanding morphological processing. Language and Cognitive Processes, 9, 271-294.

Taft, M. \& Chen, H.C. (1992). Judging homophony in Chinese: The influence of tones. In H.C. Chen \& O.J.L. Tzeng (Eds.), Language processing in Chinese (pp. 151-172). Amsterdam: Elsevier Science Publishers.

Taft, M. \& Forster, K.I. (1975). Lexical storage and retrieval of polymorphemic and polysyllabic words. Journal of Verbal Learning and Verbal Behaviour, 14, 638-647.

Taft, M. \& Hambly, G. (1985). The influence of orthography on phonological representations in the lexicon. Journal of Memory and Language, 24, 320-335.

Taft, M. \& van Graan, F. (1998). Lack of phonological mediation in a semantic categorization task. Journal of Memory and Language, 38, 203-224.

Taft, M. \& Zhu, X. (1995). The representation of bound morphemes in the lexicon: a Chinese study. In L. Feldman (Ed.), Morphological aspects of language processing (pp. 293-316). Hillsdale, New Jersey: Lawrence Erlbaum Associates. 
Taft, M., Liu, Y. \& Zhu, X. (1999). Morphemic processing in reading Chinese. In J. Wang, A.W. Inhoff \& H.-C. Chen (Eds.), Reading Chinese script: A cognitive analysis (pp. 91113). Mahwah, New Jersey: Lawrence Erlbaum Associates.

Taraban, R. \& McClelland, J.L. (1987). Conspiracy effects in word pronunciation. Journal of Memory and Language, 26, 608-631.

Treiman, R. \& Chafetz, J. (1987). Are there onset-and rime-like units in printed words? In M. Coltheart (Ed.), Attention and performance XII: The psychology of reading (pp. 281-298). Hillsdale, New Jersey: Lawrence Erlbaum Associates.

Treiman, R. \& Zukowski, A. (1988). Units in reading and spelling. Journal of Memory and Language, 27, 466-477.

Treiman, R., Goswami, U. \& Bruck, M. (1990). Not all nonwords are alike: Implications for reading development and theory. Memory and Cognition, 18, 559-567.

Treiman, R., Mullennix, J., Bijeljac-Babic, R. \& Richmond-Welty, E. (1995). The special role of rimes in the description, use, and acquisition of English orthography. Journal of Experimental Psychology: General, 124, 107-136.

Address for correspondence: Dr Jeesun Kim, Department of Psychology, School of Behavioural Sciences, The University of Melbourne, Parkville, VIC 3010, Australia

Phone: +61-3-83444303; Fax: +61-3-93476618; E-mail: jeesun@unimelb.edu.au 
Appendix: Experimental items

\begin{tabular}{|c|c|c|c|c|c|}
\hline \multicolumn{2}{|c|}{$\begin{array}{c}\text { NormaI } \\
\text { Homophones }\end{array}$} & Nonhomophones & \multicolumn{2}{|c|}{$\begin{array}{c}\text { Modified } \\
\text { Homophones }\end{array}$} & \multirow{2}{*}{$\begin{array}{c}\text { Nonhomophones } \\
\text { 結論 }\end{array}$} \\
\hline 元祖 & [援助 ]* & 直行 & 䋗理 & [ 隔離 ] & \\
\hline 救助 & [ 構造 ] & 巨物 & 文里 & [ 物理 ] & 年例 \\
\hline 前後 & [ 戰後 ] & 名所 & 昨年 & [ 弉年 ] & 爾面 \\
\hline 果實 & [ 洏失 ] & 多忙 & 各論 & [ 講論 ] & 風物 \\
\hline 筒時 & [ 殷親 ] & 失性 & 國利 & [ 霵理 ] & 名目 \\
\hline 緭費 & ［僰備 ] & 复复 & 學文 & [ 肛門 ] & 疅立 \\
\hline 景氣 & [ 競技 ] & 異筫 & 發論 & [ 反諭 ] & 上流 \\
\hline 武力 & [ 無力 ] & 標本 & 毒物 & ［動物 ] & 終末 \\
\hline 母子 & [ 帽子 ] & 比較 & 法例 & ［凡例 ] & 成立 \\
\hline 東空 & [ 同空 ] & 創刊 & 分量 & [ 不良 ] & 力量 \\
\hline 部蔟 & [ 不足 ] & 敗因 & 分離 & [ 不租 ] & 公民 \\
\hline 凡人 & [ 犯人 ] & 具現 & 緾路 & [ 激怒] & 農林 \\
\hline 速成 & ［雷性 ] & 比重 & 新粶 & ［實錄 ] & 目錄 \\
\hline 神父 & [ 新婦 ] & 用件 & 略歷 & [ 掦力 ] & 切迫 \\
\hline 分身 & [ 楚身 ] & 落書 & 月利 & [ 原理 ] & 植木 \\
\hline 方位 & [ 防衛 ] & 夎信 & 一年 & [一連 ] & 競賣 \\
\hline 山所 & [ 酸素 ] & 死活 & 長文 & [ 作文 ] & 作名 \\
\hline 公海 & [ 公害 ] & 後尾 & 層面 & ［側面 ］ & 進路 \\
\hline 美式 & [ 美食 ] & 要約 & 刑名 & [ 革命 ] & 同盟 \\
\hline \multicolumn{6}{|c|}{ * Items in [] are target homophones. } \\
\hline \multicolumn{6}{|c|}{ Experiment 2} \\
\hline \multicolumn{2}{|c|}{ Homophones } & Nonhomophones & \multicolumn{2}{|c|}{ Homophones } & Nonhomophones \\
\hline 변리 & [ 별리 ] & 묵례 & 벽력 & [ 병력 ] & 풍미 \\
\hline 항문 & [ 학문 ] & 순열 & 분럃 & [ 불량 ] & 함락 \\
\hline 양력 & [ 약력 ] & 논리 & 성량 & [ 성냥 ] & 강력 \\
\hline 착오 & [ 차고 ] & 두처 & 소거 & [ 속어 ] & 곡마 \\
\hline 바람 & [ 발암 ] & 반영 & 문리 & [ 물뢰 ] & 기반 \\
\hline 산림 & [ 살림 ] & 심려 & 열락 & [ 연락 ] & 능력 \\
\hline 둥물 & [ 독물 ] & 잠입 & 작년 & [ 장년 ] & 단련 \\
\hline 격노 & [ 경로 ] & 자립 & 시련 & [ 실연 ] & 모교 \\
\hline 경리 & [ 격리 ] & 진료 & 장문 & [ 작문 ] & 법인 \\
\hline 공명 & [ 곡명 ] & 차량 & 밀애 & [ 미래 ] & 출입 \\
\hline \multicolumn{6}{|c|}{ Experiment 3} \\
\hline \multicolumn{2}{|c|}{ Homophones } & Nonhomophones & \multicolumn{2}{|c|}{ Homophones } & Nonhomophones \\
\hline 달녁 & [ 달력 ] & 답너 & 경뎍 & [ 격렬 ] & 격료 \\
\hline 명녕 & [ 명령 ] & 벽뉴 & 골란 & [ 곤란 ] & 설리 \\
\hline 악날 & [ 악랄 ] & 월 닉 & 삭류 & [ 상류 ] & 궁루 \\
\hline 함낙 & [ 함락 ] & 병닐 & 궐리 & [ 권리 ] & 담란 \\
\hline 협녁 & [협력 ] & 감난 & 놀리 & [ 논리 ] & 착림 \\
\hline 속녁 & [ 속력 ] & 종넘 & 달란 & [ 단란 ] & 합록 \\
\hline 밀념 & [ 밀림 ] & 막누 & 슥리 & [ 승리 ] & 눌리 \\
\hline 염녀 & [ 염려 ] & 용노 & 말류 & [ 만류 ] & 멱림 \\
\hline 압녁 & [ 압력 ] & 솔난 & 발란 & [ 반란 ] & 할답 \\
\hline 섭니 & [ 섭리 ] & 엄녁 & 동립 & [ 독립 ] & 몬란 \\
\hline
\end{tabular}

